\title{
Systemic bee venom exerts anti-arthritic and anti-inflammatory properties in a rat model of arthritis
}

\author{
DOAA MOHAMED EL-TEDAWY, MOHAMMAD MAHMOUD ABD-ALHASEEB, \\ MAGED WASFY HELMY and ASSER IBRAHIM GHONEIM
}

Department of Pharmacology and Toxicology, Faculty of Pharmacy, Damanhour University, Damanhour, Beheira 22516, Egypt

Received October 12, 2019; Accepted April 16, 2020

DOI: $10.3892 /$ br.2020.1327

\begin{abstract}
Bee venom (BV) is widely used as a traditional China medicine to treat various conditions, including rheumatoid arthritis (RA). The aim of the present study was to evaluate the effects of systemic BV $(60 \mathrm{mg} / \mathrm{kg})$ as an anti-arthritic natural product, compare it with Methotrexate and determine the possible underlying mechanisms of BV action using complete Freund's adjuvant-induced arthritic rats. The development of signs of RA signs (knee joint circumference and arthritis scoring index) was evaluated. Erythrocyte sedimentation rate, serum tumor necrosis factor- $\alpha$ (TNF- $\alpha$ ) and serum interleukin-1 $\beta$ (IL-1 $\beta$ ) levels were measured at the end of the study. Histopathological examination followed by immunostaining of NF- $\mathrm{BB}$ (P65) was performed on the affected knee joints. Additionally, in vitro cyclooxygenase (COX) inhibition activity, carrageenan paw edema test and acetic acid writhing tests were performed to evaluate the anti-inflammatory and analgesic effects of the assessed dose and compared with diclofenac. An acute toxicity test was performed to establish the safety of BV at high doses. The results of the present study highlighted the potential of systemic BV on preventing the development of signs of RA. BV also significantly reduced serum levels of TNF- $\alpha$, IL- $1 \beta$ and $\mathrm{NF}-\kappa \mathrm{B}$ in the affected joints. In addition to its potent analgesic activity, BV exhibited favorable inhibitory activity of the COX pathway in both in vivo and in vitro models. Therefore, high dose administration of systemic BV displayed safe and promising anti-arthritic, anti-inflammatory and analgesic properties through regulation of different mechanisms associated with the pathogenesis of RA.
\end{abstract}

Correspondence to: Dr Mohammad Mahmoud Abd-Alhaseeb, Department of Pharmacology and Toxicology, Faculty of Pharmacy, Damanhour University, Elgomhoria Street, Damanhour, Beheira 22516, Egypt

E-mail: m.abdelhasseb@pharm.dmu.edu.eg

Key words: bee venom, rheumatoid arthritis, Complete Freund's adjuvant, methotrexate, nuclear factor-кB, cyclooxygenase

\section{Introduction}

Rheumatoid arthritis (RA) is a common form of arthritis which primarily affects multiple joints, but can also cause damage to other organs, known as extra-articular manifestations (1). The symptoms associated with such conditions include pain, swollen joints, stiffness with synovitis, and progressive cartilage and bone erosion. RA can lead to serious functional disability if it is not properly managed (2).

Although the etiology of RA remains incompletely understood, previous studies have suggested that the activation of $\mathrm{T}$ cells potentiates a subsequent activation of other immune cells such as B cells, fibroblasts and macrophages resulting in a complex network of continuously secreted pro-inflammatory cytokines (3-5).

The overproduction of pro-inflammatory cytokines, particularly tumor necrosis factor (TNF- $\alpha$ ) and interleukin- $1 \beta$ (IL-1 $\beta$ ) are crucially involved in the pathogenesis and progression of RA $(6,7)$.

Nuclear factor- $\mathrm{KB}(\mathrm{NF}-\mathrm{\kappa B})$ activation has also been shown to be associated with the pathogenesis of RA, resulting in cartilage and bone destruction (8). The NF- $\mathrm{KB}$ pathway was demonstrated to result in upregulation of pro-inflammatory cyclooxygenase-2 (COX-2) levels and inducible nitric oxide synthase (iNOS), leading to the subsequent production of pro-inflammatory prostaglandins (PGs) and nitric oxide, which lead to further articular damage and induced hyperalgesia (9-11).

The use of alternative natural products for treatment of RA is gaining increasing interest. Bee venom (BV), obtained from Apis mellifera, contains different peptides, including melittin, apamin, adolapin and mast cell degranulating peptide (12). BV is widely used in traditional Chinese medicine for the treatment of inflammatory diseases, such as RA and to alleviate the associated pain $(13,14)$.

Additionally, BV has been reported to exert promising anti-inflammatory and immunomodulatory properties (15-17).

Thus, the aim of the present study was to evaluate the anti-arthritic activity of $\mathrm{BV}$, and the possible underlying immunomodulatory mechanisms of systemic BV in RA using an in vivo experimental model.

\section{Materials and methods}

Chemicals and solvents. Methotrexate was purchased from Mylan N.V. BV was purchased from Apis Injeel ${ }^{\circledR}$ 
(Heel, GMBH). Complete Freund's adjuvant (CFA) was purchased from Sigma-Aldrich; Merck KGaA. TNF- $\alpha$ (cat. no. CSB-E11987r) and IL-1 $\beta$ (cat. no. CSB-E08055r) ELISA kits were purchased from CUSABIO TECHNOLOGY LLC. COX inhibitor screening assay kit (cat. no. 560131) was purchased from Cayman Chemical Company. Other reagents used were purchased from Sigma-Aldrich; Merck KGaA.

Animals. Studies were performed on adult male Wistar rats weighing (150-200 g), and were obtained from the animal house of VACSERA Co. Animals were maintained in a controlled environment at the ambient temperature, with ad libitum access to food and water. Animals were allowed to acclimatize for 7 days prior to initiation of experiments. The study time plan was designed for 21 days during which the animals were housed in cages of suitable sizes (maximum of 3 animals per cage) to ensure animal comfort.

Sodium pentobarbital was used to anesthetize the animals before the induction of arthritis and at the end of the study to euthanize the animals via intraperitoneal (i.p.) injection $(800 \mathrm{mg} / \mathrm{kg})(18)$. Ethical approval was obtained for all the procedures from the Ethics Committee of the Faculty of Pharmacy, Damanhour University, (Damanhour, Egypt) (approval no. 717PO5).

Induction of arthritis. Animals were anesthetized using sodium pentobarbital (50 mg/kg, i.p.) (19). Arthritis was induced by intra-articular injection of $0.3 \mathrm{ml} \mathrm{CFA}(1 \mathrm{mg} / \mathrm{ml})$ to the right knee joint, as described previously (20). As a control, $0.3 \mathrm{ml}$ saline was injected into the left knee joint. The point of injection was marked to ensure consistency in the knee circumference follow up readings. Rats were considered arthritic if redness and joint swelling was observed in at least joint. The signs were assessed according to a scoring system as described below.

Treatment protocol and experimental design. A total of 20 rats were randomly assigned to one of four groups ( $n=5$ per group) as follows: i) Normal healthy rats; ii) arthritic rats that were treated with saline as a negative control; iii) arthritic rats treated with methotrexate (2 mg/kg/week, i.p.) as a standard drug (21); and iv) arthritic rats treated with BV $(60 \mathrm{mg} / \mathrm{kg} /$ day, i.p. $)$. All the treatments with methotrexate or BV started one day after the induction procedure was performed, and was performed consistently for 21 days. BV dose was selected through screening of various doses of $\mathrm{BV}(5,10,15,30,45$ and $60 \mathrm{mg} / \mathrm{kg})$ against the stable standard methotrexate, and $60 \mathrm{mg} / \mathrm{kg}$ BV was found to the most efficacious dose (Table S1).

Evaluation of knee joint edema. The circumferences of the knee joint were measured at the previously marked points using flexible tape prior to and following the induction of arthritis. Subsequently, the circumference was measured periodically every week for 21 days (22). On day 21; the rats were euthanized. Blood and serum samples were collected for further biochemical analysis. Knee joints were harvested and preserved in buffered formalin-saline (10\%) at room temperature for $48 \mathrm{~h}$ for follow up histopathological examination.

Scoring index of arthritic manifestations. Rats were evaluated every 6 days from day 1 for symptoms of RA and other signs of inflammation. The severity of the symptoms in each rat was evaluated by grading the four knee joints on a scale of 0-3 according to the variations in erythema, edema, presence of nodules and the involvement of other non-injected joints with a total score of 12 per rat. The scores were defined as follows: 0 , erythema, no swelling with no nodules; 1 , erythema, mild swelling with no nodules. 2 , erythema, moderate swelling with or without nodules; and 3, erythema with severe swelling limiting the overall movement and presence of nodules or lesions, as described previously $(23,24)$.

Erythrocyte sedimentation rate (ESR). ESR is a non-specific test that indirectly measures the presence of inflammation in a whole blood sample. ESR was evaluated using the Westergren method (25). Blood was drawn from each rat and was placed into disposable vacuum Westergren ESR tubes containing sodium citrate from Wei Hai Kangzhou Biotechnology Co. Ltd. The tubes were allowed to stand vertically for 1 and $2 \mathrm{~h}$. The drop in erythrocyte level was measured and was considered to represent the ESR value (26).

Measurement of the serum levels of TNF- $\alpha$ and $I L-1 \beta$ using ELISA. TNF- $\alpha$ and IL- $1 \beta$ levels were assessed using ELISA. An antibody specific for TNF- $\alpha$ or IL- $1 \beta$ had been pre-coated separately onto microplates, then both the standard and the serum samples were placed into wells to form an immobilized antibody. Subsequent addition of biotin-conjugated antibody then avidin conjugated horseradish peroxidase, followed by a substrate solution was added to the wells resulting in the development of a color if the tested antibody was present in the serum. The intensity of the color was measured and was relative to the quantity of TNF- $\alpha$ or IL- $1 \beta$ bound antibody (27).

Histopathological examination of the knee joints in adjuvant-induced arthritic rats. The preserved knee joints were decalcified in EDTA for 4 weeks, then embedded in paraffin blocks. The blocks were sliced into sections $4 \mu \mathrm{m}$ thick, and the joint sections were stained with Mayer hematoxylin solution for $8 \mathrm{~min}$ and eosin $\mathrm{Y}$ solution for $1 \mathrm{~min}$, both at room temperature.

$H \& E$ stained sections were scored for changes in cell infiltration, synovitis, synovial proliferation and cartilage or bone erosion. The sections were assessed on a scale of 0-3, and classified as follows: 0, No cell infiltration, no synovitis, intact synovial lining and no damage to the cartilage or the bone; 1 , small count of cell infiltration, mild synovitis, limited pannus formation and no apparent damage to the cartilage or the bones; 2, moderate density of infiltrating cells, moderate synovitis, moderate pannus formation and moderate lesions in the cartilage or the bone; and 3, large quantities of infiltrating cells, severe synovitis, severe pannus formation and extensive damage to the cartilage or the bones (28).

Immunostaining for $N F-\kappa B(p 65)$ expression in adjuvant-induced arthritic rats. CFA induced arthritic knee joints were subjected to an NF- $\kappa \mathrm{B}$ (p65) immunostaining kit obtained from Thermo Fisher Scientific, Inc. (cat. no. RB-1638-R7), and performed according to the manufacturer's protocol. Staining was assessed using a light microscope at a magnification of $x 400$. Images were analysed using ImageJ; the percentage of area stained and the intensity of the NF-kB (p65) staining were assessed (29). 

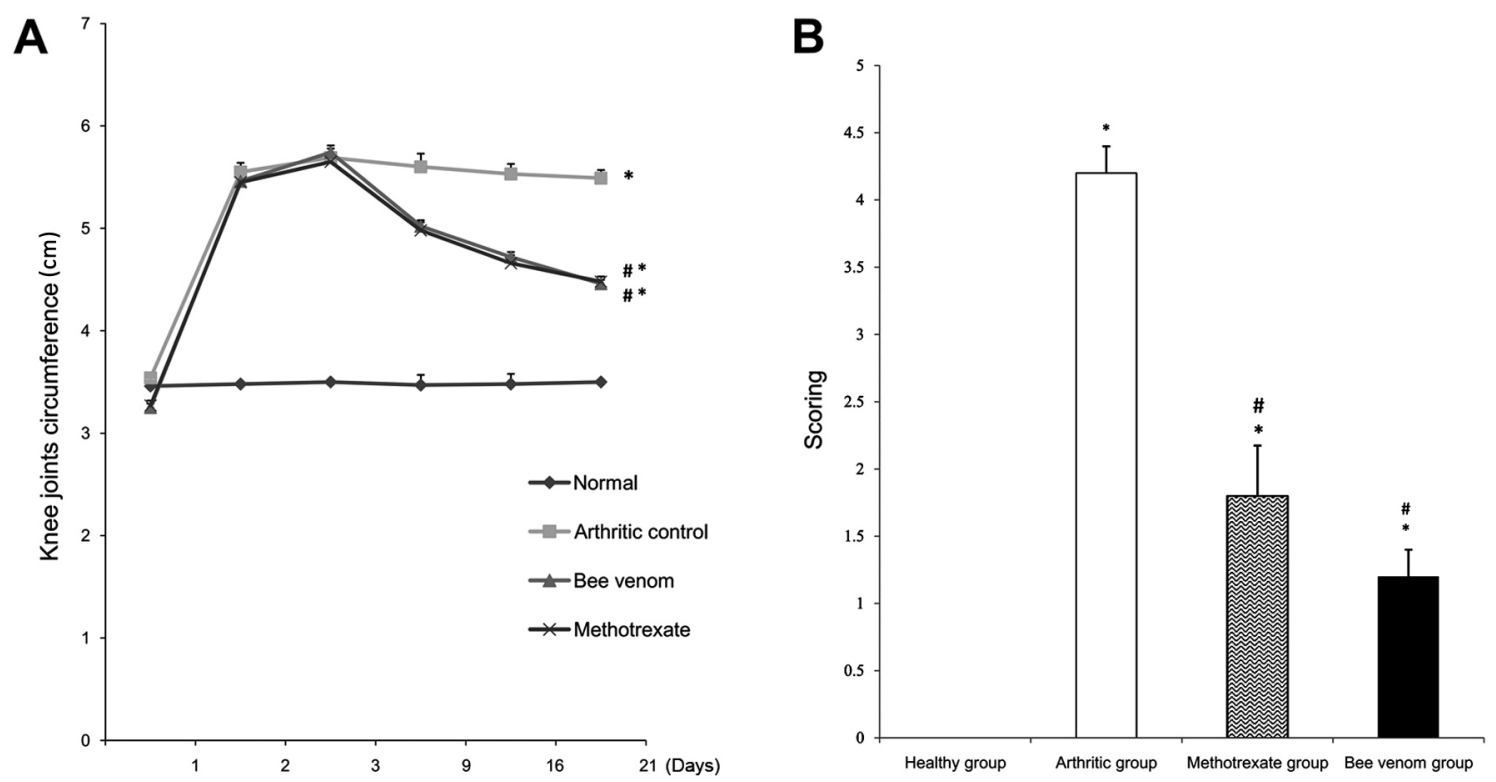

Figure 1. Effect of bee venom and methotrexate on adjuvant induced arthritic rats. (A) Knee joint circumference measurements. (B) Arthritis index score. Data are expressed as the mean \pm the standard error of the mean, $n=5$. ${ }^{*} \mathrm{P}<0.05$ vs. healthy group; ${ }^{\#} \mathrm{P}<0.05$ vs. arthritic control group.

Determination of in-vitro COX activity. COX activity was evaluated using a COX (ovine) Inhibitor Screening assay kit that included both ovine COX-1 and human recombinant COX-2 enzymes. The assay was used to screen isozyme-specific inhibitors by direct measurement of PGF2 $\alpha$ which is produced by the reduction of $\mathrm{COX}$-derived $\mathrm{PGH} 2$ by $\mathrm{SnCl} 2$. Finally, the yield was evaluated using enzyme immunoassay for quantification, as described previously $(30,31)$.

Carrageenan paw edema. Acute anti-inflammatory activity was evaluated using a carrageenan-induced rat paw edema test. A total of 15 male Wistar rats were divided into 3 groups. After injecting BV $(60 \mathrm{mg} / \mathrm{kg}$, i.p.), rats were treated with diclofenac sodium as a standard drug (5 mg/kg, i.p.) (32). The rats were challenged by subcutaneous injection of $0.1 \mathrm{ml}$ $1 \%$ carrageenan solution into the plantar side of the right hind paw. The paw volume was measured using a micrometer caliper, before, and 1, 3 and $4 \mathrm{~h}$ after the injection of the carrageenan solution $(33,34)$.

Acetic acid writhing test. To measure the analgesic activity, 20 male albino mice (weighting 20-25 g) were divided into 4 groups $(n=5$ per group). One group contained healthy rats. Another group served as a control that only received saline as a treatment. The other two groups were treated with wither diclofenac ( $5 \mathrm{mg} / \mathrm{kg}$, i.p.) (32) or BV (60 mg/kg, i.p.), prior to administration of $0.1 \mathrm{ml} / 10 \mathrm{~g} 1 \%$ acetic acid (i.p.). The number of writhes or abdominal stretches were counted for $20 \mathrm{~min}$ in the mice $(35,36)$.

Acute toxicity study in mice. Acute toxicity in mice was assessed as described previously (37). A total of 20 male albino mice were sorted into 4 groups $(n=5)$. The mice were housed 5 days prior to the start of the study, and the animals were maintained as described above. BV was administrated as a single i.p. dose $(60,600$ or $1,200 \mathrm{mg} / \mathrm{kg})$, respectively, to 3 of the groups, and the remaining group served as the control. Following BV treatment, the mice were observed continuously every $2 \mathrm{~h}$ for $6 \mathrm{~h}$, then daily for 3 days, for any changes in the general behavior and any signs of toxic manifestations, such as tremors, convulsions, loss of right reflex, muscle spasm, decreased motor activity, sedation, writhing, respiration and mortalities. Blood samples were collected after 3 days for further assessment of liver function using an alanine aminotransferase (ALT) test using a spectrophotometric assay with diagnostic kits purchased from Sigma-Aldrich; Merck KGaA as described previously (38). In addition, kidney function tests were guided by the determination of serum creatinine levels as described previously (39).

Statistical analysis of the data. Results are expressed as the mean \pm the standard error of the mean. Analysis was performed using SPSS version 15.0 (SPSS, Inc.). One-way ANOVA followed by a Bonferroni post hoc test was used to compare the differences between the groups. $\mathrm{P}<0.05$ was considered to indicate a statistically significant difference.

Analysis of immunostaining was analysed using ImageJ version 1.45f 112_1.8.0 (National Institutes of Health). The percentage of stained area was compared between groups using a one-way ANOVA followed by a Bonferroni post hoc test. $\mathrm{P}<0.05$ was considered to indicate a statistically significant difference.

\section{Results}

Knee joint circumference. Immunization of the rats with CFA resulted in the induction of prominent arthritis, as shown by the significant increase in knee joint swelling and an increase in the knee joint circumferences compared with the healthy controls $(\mathrm{P}<0.05)$. Individual treatments with methotrexate and BV significantly reduced the knee joint swelling circumferences compared with the control arthritic group (Fig. 1A; both $\mathrm{P}<0.05$ ).

Arthritic index. Rats injected with CFA showed a significant increase in the arthritis index compared with the healthy rats 

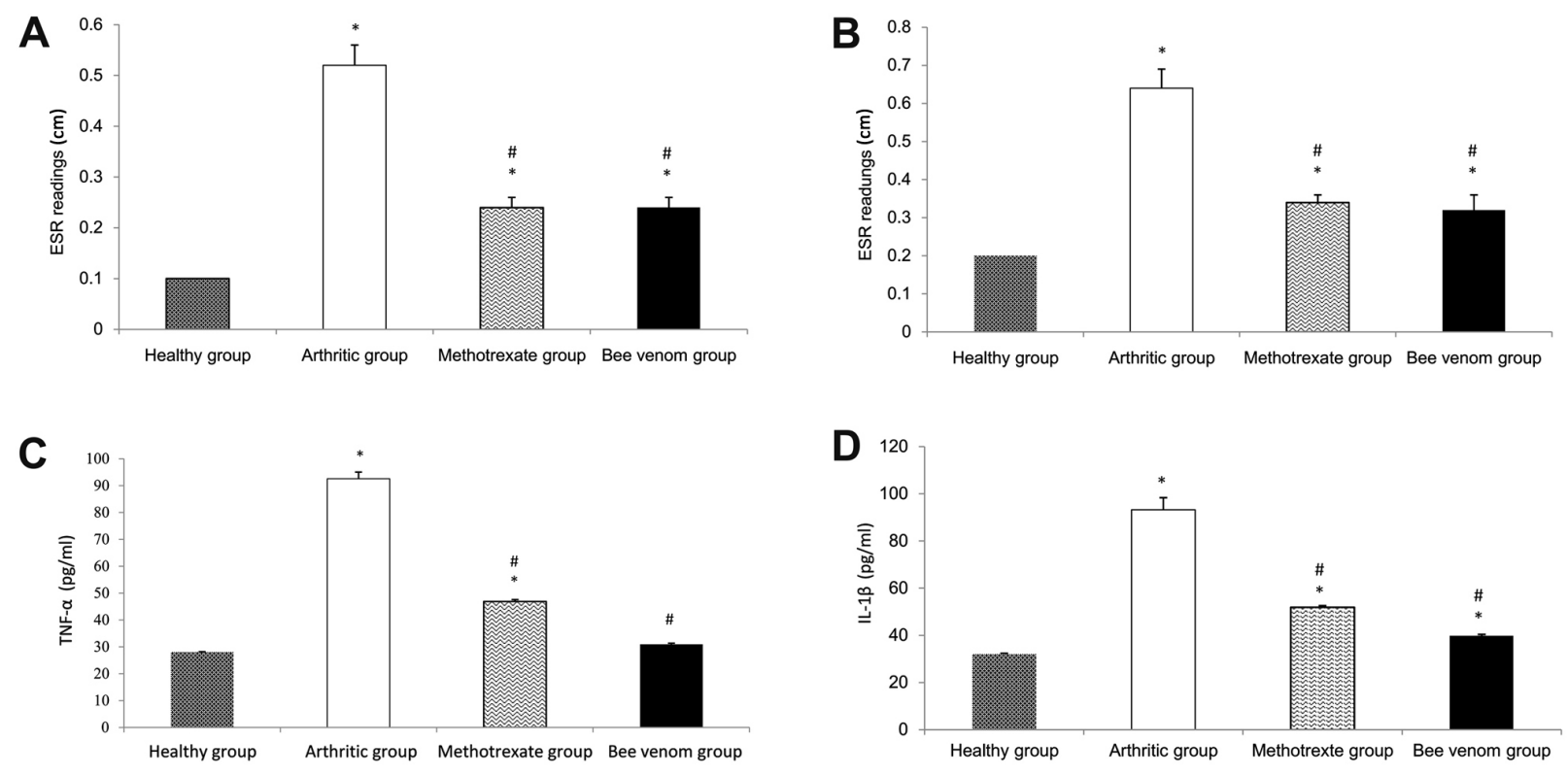

Figure 2. Effect of bee venom and methotrexate on adjuvant-induced arthritic rats. ESR after (A) $1 \mathrm{~h}$ and (B) $2 \mathrm{~h}$. Serum concentration levels of (C) TNF- $\alpha$ and (D) IL-1 $\beta$. ${ }^{*} \mathrm{P}<0.05$ vs. normal healthy group; ${ }^{\mathrm{P}} \mathrm{P}<0.05$ vs. arthritic control group. ESR, erythrocyte sedimentation rate; TNF- $\alpha$, tumor-necrosis-factor- $\alpha$; IL-1 $\beta$, interleukin- $1 \beta$.
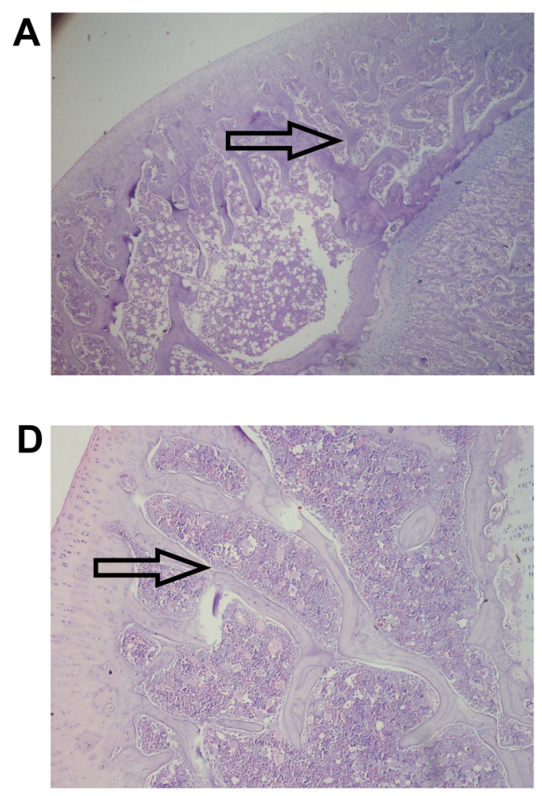

B

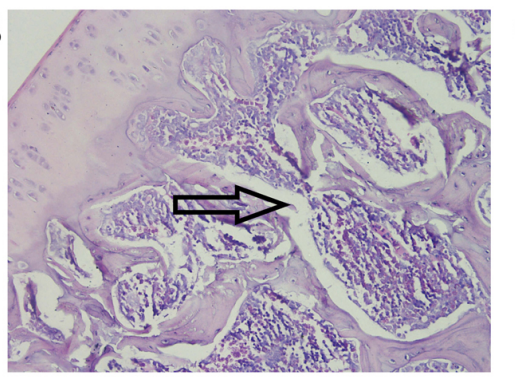

E

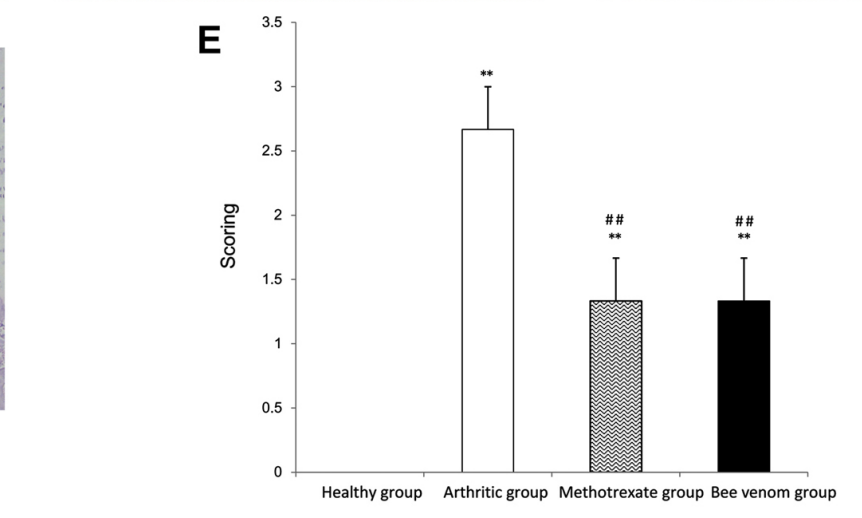

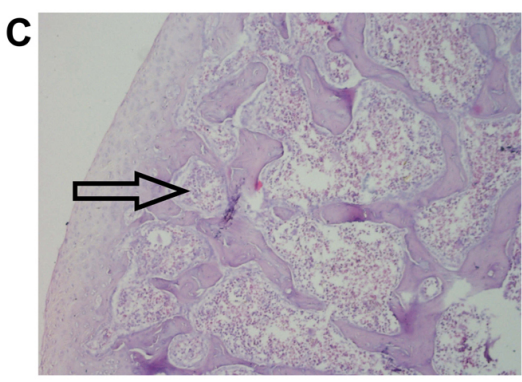

(1)

Figure 3. Histopathological examination of knee joints using hematoxylin and eosin staining showing the effect of bee venom and methotrexate treatment in adjuvant-induced arthritic rats. Knee section from (A) normal control group; (B) arthritic group; (C) methotrexate group; and (D) bee venom treated group. Magnification, $\mathrm{x} 400$. (E) Histopathological scoring. Data are expressed as the mean \pm the standard error of the mean, $\mathrm{n}=5$. ${ }^{* *} \mathrm{P}<0.01 \mathrm{vs}$. healthy group; ${ }^{\# \#} \mathrm{P}<0.01$ vs. arthritic control group.

$(\mathrm{P}<0.05)$. Rats treated with methotrexate or BV showed a significant reduction in the arthritis index at the end of the study (day 21) compared with the arthritic control group (Fig. 1B; both $\mathrm{P}<0.05$ ).

ESR. The arthritic group showed a significant increase in ESR values compared with the normal control $(\mathrm{P}<0.05)$. Methotrexate and BV significantly reduced the increase in ESR levels (Fig. 2A and B; both $\mathrm{P}<0.05$ ).
Serum TNF- $\alpha$ and IL-1 $\beta$ levels. The arthritic group showed a noticeable increase ( $\sim 3$-fold) in both the levels of TNF- $\alpha$ and IL-1 $\beta$, and this increase was consistent throughout the entire duration of the study compared with the normal control group. Treatment with methotrexate significantly reduced TNF- $\alpha$ and IL- $1 \beta$ levels compared with the arthritic control group. Similarly, treatment with BV resulted in a reduction in serum TNF- $\alpha$ and IL- $1 \beta$ levels compared with the methotrexate group, reaching the levels of the normal control rats Fig. $2 \mathrm{C}$ and D. 
Table I. Assessment of in vitro $\mathrm{COX}$ inhibition $\mathrm{IC}_{50}$ values of bee venom.

\begin{tabular}{lccc}
\hline Treatment & $\begin{array}{c}\mathrm{COX}-1 \\
\mathrm{IC}_{50}, \mu \mathrm{M}\end{array}$ & $\begin{array}{c}\mathrm{COX}-2 \\
\mathrm{IC}_{50}, \mu \mathrm{M}\end{array}$ & $\begin{array}{c}\mathrm{COX}-2 \\
\text { selectivity index }\end{array}$ \\
\hline Celecoxib & 15.1 & 0.049 & 308 \\
Indomethacin & 0.041 & 0.51 & 0.08 \\
Diclofenac sodium & 3.8 & 0.84 & 4.5 \\
Bee venom & 9.41 & 0.15 & 63 \\
\hline
\end{tabular}

Histopathological examination. Histopathological examination of sections of the knee joint showed apparent infiltration of mononuclear inflammatory cells, and cell debris with a high incidence of cartilage destruction and pannus development in the arthritic group. Treatment with methotrexate or BV significantly reduced the histopathological score $(\mathrm{P}<0.01)$, and the sections showed notably reduced inflammatory cell infiltration and pannus formation in the synovium and surrounding tissues, and the sections maintained most of the normal joint and tissue construction and integrity when compared with the arthritic control group (Fig. 3).

Immunostaining for $N F-\kappa B$ (p65) expression in arthritic rats. Healthy normal rats showed nearly no staining for NF- $\kappa \mathrm{B}$ p65, whereas the arthritic control knee joint sections exhibited the highest intensity of immunostaining and was significantly greater compared with the normal, methotrexate and BV treated groups $(\mathrm{P}<0.01)$. Methotrexate treatment resulted in moderate levels of staining, and treatment with $\mathrm{BV}$ resulted in a mild density of NF- $\kappa \mathrm{B}$ immunostaining in the affected knee joints. The percentage of the area stained was scored to validate the difference in the immunostaining intensity (Fig. 4). A greater intensity of the color represented an increase in $\mathrm{NF}-\kappa \mathrm{B}(\mathrm{p} 65)$ expression.

In vitro $C O X$ inhibition, $I_{50}$ and $C O X-2$ selectivity index. $\mathrm{BV}$ inhibited COX-2 at relatively lower $\mathrm{IC}_{50}$ doses compared with indomethacin and diclofenac sodium. The COX-2 selectivity index of BV was higher compared with both indomethacin and diclofenac sodium (Table I).

In vivo anti-inflammatory and analgesic activity of $B V$. BV exhibited systemic anti-inflammatory activity that was shown by the $40.74 \%$ reduction in hind paw carrageenan-induced edema compared with diclofenac sodium (37.03\%) at $4 \mathrm{~h}$. $\mathrm{BV}$ also demonstrated notable analgesic activity as shown by the comparatively lower number of abdominal writhes when compared with the control or diclofenac sodium groups (Table II).

Acute toxicity study. Administration of BV in the albino mice did not exhibit any toxic effects up to and including a dose of $1,200 \mathrm{mg} / \mathrm{kg}$. The mice did not demonstrate any signs of toxicity and there were no mortalities.

Liver function was assessed by performing an alanine aminotransferase (ALT) test. ALT levels in the normal control group were $21.8 \pm 0.8 \mathrm{U} / 1$; in the mice treated with
$60 \mathrm{mg} / \mathrm{kg} \mathrm{BV}, 27 \pm 0.89 \mathrm{U} / \mathrm{l}$; mice treated with $600 \mathrm{mg} / \mathrm{kg}$ $\mathrm{BV}, 36.6 \pm 0.5 \mathrm{U} / \mathrm{l}$; and in the mice treated with $1,200 \mathrm{mg} / \mathrm{kg}$, $71.6 \pm 1.96 \mathrm{U} / 1$.

Kidney function was preliminarily assessed based on the concentration of serum creatinine. In the normal control group, serum creatinine levels were $0.27 \pm 0.01 \mathrm{mg} / \mathrm{dl}$; in the mice treated with $60 \mathrm{mg} / \mathrm{kg} \mathrm{BV}, 0.31 \pm 0.008 \mathrm{mg} / \mathrm{dl}$; mice treated with $600 \mathrm{mg} / \mathrm{kg} \mathrm{BV}, 0.39 \pm 0.007 \mathrm{mg} / \mathrm{dl}$; and in the mice treated with $1,200 \mathrm{mg} / \mathrm{kg} \mathrm{BV} 0.47 \pm 0.009 \mathrm{mg} / \mathrm{dl}$.

\section{Discussion}

RA is one of the most common autoimmune diseases. The overall age-standardized prevalence and incidence rates have been increasing globally (40) to almost affect $\sim 1 \%$ of the worldwide population (2). The pathophysiology of RA involves the contribution of several complex and connected inflammatory pathways (4).

BV has been widely used in traditional Chinese medicine to alleviate pain and inflammation during chronic inflammatory conditions such as RA $(13,41)$.

Several studies have assessed the effects of administration of different doses of BV via different routes of administration to determine a suitable dosing regimen for management of arthritis. For example, BV treatment was administrated subcutaneously at zusanli acupoint, and it exhibited potent anti-arthritic activity, although it was not compared with methotrexate (42). In addition, another study demonstrated that concurrent treatment of $\mathrm{BV}$ at zusanli acupoint with methotrexate in adjuvant-induced arthritis was more effective than methotrexate alone (29). Additionally, BV administered i.p. $20 \mu \mathrm{l} / 100 \mathrm{~g} /$ day in collagen induced arthritis (14), and up to $20 \mathrm{mg} / \mathrm{kg}$ intraperitoneally for adjuvant-induced arthritis (43) both showed good anti-arthritic properties, although these were not compared with a standard treatment.

The primary purpose of the present study was to evaluate the activity of i.p. BV, and the results of BV treatment showed it may exhibit potential for treatment of RA.

In the present study, induction of arthritis was performed using unilateral intra-articular injection of CFA. Previous studies reported the competence of CFA to induce systemic arthritis in rats $(22,44,45)$. CFA-induced arthritis models in rats were found to result in histological and immunological manifestations of RA. This provided a practical model for investigating systemic $\mathrm{BV}$ as a potential anti-arthritic agent (46).

Injection of CFA in the knee joint was shown to produce significantedema in the affected joint and a corresponding increase in the arthritis scoring index within 2 days when compared with the healthy control. Histopathological examination demonstrated the presence of a high density of cell infiltration, alterations in joint integrity and overexpression of $N F-\kappa B$ in the affected joint. Additionally, the arthritic group also showed a significant increase in ESR values, serum TNF $\alpha$ and IL-1 $\beta$ levels. All these changes showed successful induction of arthritis by CFA.

BV was administered by i.p. injection of $60 \mathrm{mg} / \mathrm{kg}$. The dose was selected according to preliminary testing of a range of doses. BV $60 \mathrm{mg} / \mathrm{kg}$ was selected as it showed the most prominent anti-arthritic activity based on biochemical and histopathological examination (data not shown). Systemic injection of BV 
Table II. Effect of BV on acetic acid writhing test and carrageenan induced paw edema.

\begin{tabular}{|c|c|c|c|c|c|c|}
\hline \multirow{4}{*}{$\begin{array}{l}\text { Groups } \\
\text { Normal control }\end{array}$} & \multirow{2}{*}{\multicolumn{2}{|c|}{ Analgesic activity }} & \multicolumn{4}{|c|}{ Anti-inflammatory activity } \\
\hline & & \multirow{3}{*}{$\begin{array}{c}\begin{array}{c}\text { Percentage } \\
\text { inhibition }\end{array} \\
0\end{array}$} & \multirow{2}{*}{\multicolumn{3}{|c|}{$\begin{array}{c}\text { Percentage change in } \\
\text { paw volume, mean } \pm \text { SEM }\end{array}$}} & \multirow{3}{*}{$\begin{array}{l}\text { Percentage of } \\
\text { inhibition of } \\
\text { edema after } 4 \mathrm{~h}\end{array}$} \\
\hline & \multirow{2}{*}{$\begin{array}{c}\begin{array}{c}\text { Number of writhes } \\
\text { in } 20 \mathrm{~min}\end{array} \\
0\end{array}$} & & & & & \\
\hline & & & $1 \mathrm{~h}$ & $3 \mathrm{~h}$ & $4 \mathrm{~h}$ & \\
\hline Arthritic control & $58 \pm 0.58^{\mathrm{a}}$ & 0 & $0.32 \pm 0.02$ & $0.44 \pm 0.04$ & $0.54 \pm 0.02$ & 0 \\
\hline Diclofenac sodium & $22 \pm 0.58^{\mathrm{a}, \mathrm{b}}$ & 62.06 & $0.22 \pm 0.02$ & $0.3 \pm 0.0$ & $0.34 \pm 0.02^{\mathrm{b}}$ & 37.03 \\
\hline $\mathrm{BV}$ & $16 \pm 0.51^{\mathrm{a}, \mathrm{b}}$ & 72.41 & $0.22 \pm 0.02$ & $0.28 \pm 0.02$ & $0.32 \pm 0.02^{\mathrm{b}}$ & 40.74 \\
\hline
\end{tabular}

${ }^{\mathrm{a}} \mathrm{P}<0.05$ vs. normal healthy control; ${ }^{\mathrm{b}} \mathrm{P}<0.05$ vs. arthritic control group. $\mathrm{BV}$, bee venom; SEM, standard error of the mean.
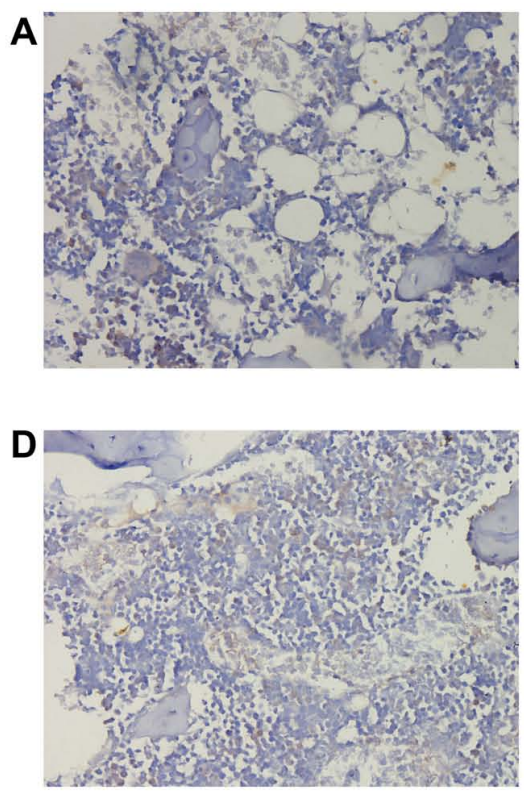
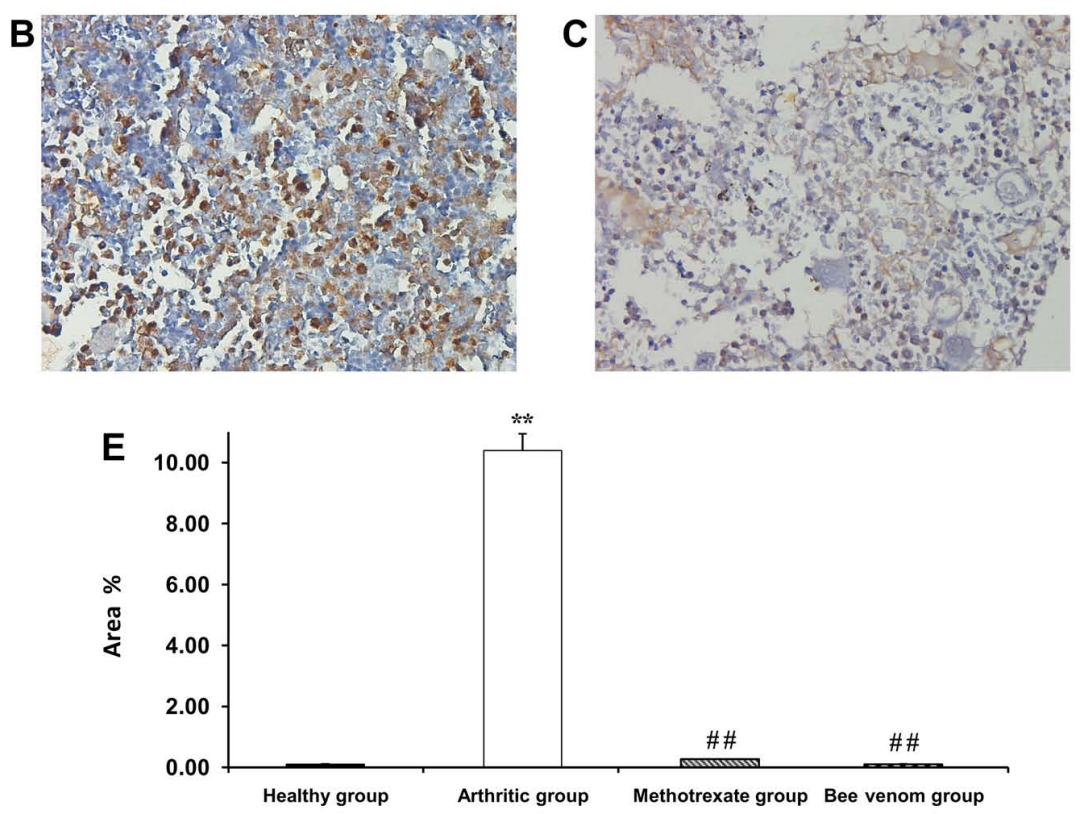

Figure 4. Effect of bee venom and methotrexate on NF- $\kappa$ B (p65) expression in knee joints of adjuvant-induced arthritic rats. Representative images of NF- $\kappa$ B immunostaining in knee sections of (A) normal control group; (B) arthritic control group, (C) methotrexate treated group and (D) bee venom treated group. (E) Percentage of area showing NF- $\kappa \mathrm{B}$ (p65) expression. ${ }^{* *} \mathrm{P}<0.01$ vs. healthy group; ${ }^{\# \#} \mathrm{P}<0.01$ vs. arthritic control group. NF- $\kappa \mathrm{B}$, nuclear factor- $\kappa \mathrm{B}$.

was previously reported to exhibit potent anti-arthritic activity at different doses $(14,43,47)$. Previous studies proposed the use of BV at different doses which varied between 1-50 mg. Doses $\leq 20 \mathrm{mg} / \mathrm{kg}$, i.p, have been evaluated for their anti-arthritic potential $(13,43)$, and another study used $50 \mathrm{mg}$ whole $\mathrm{BV}$ in dogs to determine the effect of BV on plasma cortisol levels (48).

The results of the present study showed that individual treatment of BV $(60 \mathrm{mg} / \mathrm{kg})$ and methotrexate (a widely-used standard treatment for RA) exhibited potent anti-arthritic activity, as demonstrated through a significant reduction in knee joint swelling circumferences, and a corresponding low arthritic index score. These findings agree with previous studies examining the use of methotrexate and BV $(21,43)$.

Systemic BV was found to significantly reduce ESR values compared with the arthritic group to a similar degree as the methotrexate group. Methotrexate was previously shown to be an effective agent in reducing ESR associated with RA (21). This highlights the potential of BV to reduce RA-associated inflammation.
BV significantly reduced TNF- $\alpha$ and IL-1 $\beta$ serum levels compared with the arthritic and methotrexate groups. This may explain the effectiveness of $\mathrm{BV}$ in management and alleviation of RA, as both TNF- $\alpha$ and IL-1 $\beta$ are key pro-inflammatory cytokines in the pathogenesis of RA (3).

The results of the present study agree with a previous study which showed that subcutaneous BV treatment reduced serum TNF- $\alpha$ and IL-1 $\beta$ levels in a dose-dependent manner, although they did not compare the effects of $\mathrm{BV}$ with a standard treatment (43). BV at a dose of $60 \mathrm{mg} / \mathrm{kg}$ reduced serum TNF- $\alpha$ levels to levels similar level as that observed in the healthy group.

Previous studies suggested that methotrexate reduced $\mathrm{NF}-\kappa \mathrm{B}$ expression with limited effect on TNF- $\alpha$ and IL-1 $\beta$ levels (49-51). BV and methotrexate treatment reduced $\mathrm{NF}-\kappa \mathrm{B}$ levels to a similar degree, which was upregulated in the joints of the arthritic rats. This result was consistent with a study by Darwish et al (29), where methotrexate and BV were administered at the zusanli point (an acupuncture point located below the knee). These findings confirmed the effect of systemic 
BV on the inhibition of a key inflammatory pathway which contributes to the aggravation of RA manifestations.

The anti-inflammatory activity of BV was evaluated using an in vitro assay of $\mathrm{COX}$ inhibition and confirmed in the in vivo model, carrageenan-induced paw edema. Both results suggested that BV is a more potent anti-inflammatory agent for use of inhibition of COX-2 than the previously well-established anti-inflammatory standards (diclofenac sodium and indomethacin) (52,53), and supports the hypothesis that BV is pivotal in suppressing the pro-inflammatory COX-2 levels. COX-2 inhibition was found to result in subsequent inhibition of pro-inflammatory PGs, particularly PGE2, which are partly involved in the progression of the inflammatory cascade. Previous studies showed in vitro inhibition of COX-2 activity using BV and its sub-fractions $(54,55)$.

COX-2 selectivity index of BV was higher compared with diclofenac sodium and indomethacin, which may also explain the increased anti-inflammatory properties, whilst exhibiting acceptable relative COX-1/COX-2 inhibition $(56,57)$.

The results of the acetic acid writhing test demonstrated that systemic BV had potent analgesic activity, which was evident by the lower number of abdominal writhes compared with diclofenac sodium. These findings agree with a previous study that suggested that a high dose of BV treatment by acupuncture produced potent anti-nociceptive effects, regardless of the site of BV injection in an abdominal stretch assay (42).

$\mathrm{BV}$ as an anti-nociceptive agent may explain the collective properties of BV on the inhibition of TNF- $\alpha$ levels, which results in desensitizing nociceptive primary afferents $(58,59)$. In addition, $\mathrm{BV}$-mediated inhibition of $\mathrm{NF}-\kappa \mathrm{B}$, results in subsequent inhibition of pro-inflammatory COX-2 and iNOS expression, and thus inhibition of PGE2 and $\mathrm{NO}$ as demonstrated previously in vitro (55). BV inhibited the COX-2 signaling pathway in both the in vitro assay and in the carrageenan induced paw edema, and $\mathrm{NF}-\kappa \mathrm{B}$ and $\mathrm{COX}-2$ pathways have been studied previously for their role in the induction of pain and hyperalgesia (60).

Regarding the safety of BV, doses of $60-1,200 \mathrm{mg} / \mathrm{kg}$, i.p. showed no apparent toxicological manifestations or mortalities. Previous studies also showed that there were no adverse toxic or fatal outcomes detected using a single $1,500 \mathrm{mg} / \mathrm{kg}$ dermal dose of BV $(61,62)$. However, a dose of $1,200 \mathrm{mg} / \mathrm{kg}$ (20-fold higher than the selected dose) may exert certain pathological effects on the liver and kidneys as shown by the liver and kidney function tests. Previous studies proposed similar concerns, particularly regarding the kidneys $(29,63)$.

The findings of the present study highlight the potential anti-arthritic, anti-inflammatory and anti-nociceptive mechanisms of action of BV $(60 \mathrm{mg} / \mathrm{kg} /$ day, i.p. $)$ for treatment of RA, BV exerted its effects through inhibition of basic inflammatory axes, including the combined reduction of serum TNF- $\alpha$, IL- $1 \beta$ and NF- $\kappa \mathrm{B}$ expression levels, and inhibition of the COX-2 signaling pathway, all of which are considered cornerstones in the pathophysiology of RA.

\section{Acknowledgements}

Not applicable.

\section{Funding}

No funding was received.

\section{Availability of data and materials}

The datasets used and/or analysed during the present study are available from the corresponding author on reasonable request.

\section{Authors' contributions}

All authors contributed to the study conception and design. DMET wrote the original draft of the manuscript and performed the experiments. MMAA reviewed the manuscript. MWH performed the data analysis. AIG supervised the study. All authors read and approved the final manuscript.

\section{Ethics approval and consent to participate}

Ethical approval for all the procedures was granted by the Ethics Committee of the Faculty of Pharmacy, Damanhour University, (Damanhour, Egypt) (approval no. 717PO5).

\section{Patient consent for publication}

Not applicable.

\section{Competing interests}

The authors declare that they have no competing interests and all authors confirm its accuracy.

\section{References}

1. Arnett FC, Edworthy SM, Bloch DA, Bloch DA, McShane DJ, Fries JF, Cooper NS, Healey LA, Kaplan SR, Liang MH Luthra HS, et al: The American rheumatism association 1987 revised criteria for the classification of rheumatoid arthritis. Arthritis Rheum 31: 315-324, 1988.

2. Uhlig T, Moe RH and Kvien TK: The burden of disease in rheumatoid arthritis. Pharmacoeconomics 32: 841-851, 2014.

3. Bingham CO III: The pathogenesis of rheumatoid arthritis: Pivotal cytokines involved in bone degradation and inflammation. J Rheumatol Suppl 65: 3-9, 2002.

4. Choy EH and Panayi GS: Cytokine pathways and joint inflammation in rheumatoid arthritis. N Engl J Med 344: 907-916, 2001.

5. Mateen S,Zafar A, Moin S, Khan AQ and Zubair S: Understanding the role of cytokines in the pathogenesis of rheumatoid arthritis. Clin Chim Acta 455: 161-171, 2016.

6. Matsuno H, Yudoh K, Katayama R, Nakazawa F, Uzuki M, Sawai T, Yonezawa T, Saeki Y, Panayi GS, Pitzalis C and Kimura T: The role of TNF-alpha in the pathogenesis of inflammation and joint destruction in rheumatoid arthritis (RA): A study using a human RA/SCID mouse chimera. Rheumatology (Oxford) 41: 329-337, 2002.

7. Iwakura Y: Roles of IL-1 in the development of rheumatoid arthritis: Consideration from mouse models. Cytokine Growth Factor Rev 13: 341-355, 2002.

8. Roman-Blas JA and Jimenez SA: NF-kappaB as a potential therapeutic target in osteoarthritis and rheumatoid arthritis. Osteoarthritis Cartilage 14: 839-848, 2006.

9. Crofford LJ, Tan B, McCarthy CJ and Hla T: Involvement of nuclear factor kappa $\mathrm{B}$ in the regulation of cyclooxygenase-2 expression by interleukin-1 in rheumatoid synoviocytes. Arthritis Rheum 40: 226-236, 1997.

10. Poligone $B$ and Baldwin AS: Positive and negative regulation of NF-kappaB by COX-2: roles of different prostaglandins. J Biol Chem 276: 38658-38664, 2001.

11. Yamamoto Y and Gaynor RB: Role of the NF-kappaB pathway in the pathogenesis of human disease states. Curr Mol Med 1: 287-296, 2001.

12. Rader K, Wildfeuer A, Wintersberger F, Bossinger $P$ and Mucke HW: Characterization of bee venom and its main components by high-performance liquid chromatography. J Chromatogr 408: 341-348, 1987. 
13. Kwon YB, Lee JD, Lee HJ, Han HJ, Mar WC, Kang SK, Beitz AJ and Lee JH: Bee venom injection into an acupuncture point reduces arthritis associated edema and nociceptive responses. Pain 90: 271-280, 2001.

14. Kim KW, Shin YS, Kim KS, Chang YC, Park KK, Park JB, Choe JY, Lee KG, Kang MS, Park YG and Kim CH: Suppressive effects of bee venom on the immune responses in collagen-induced arthritis in rats. Phytomedicine 15: 1099-1107, 2008

15. Hwang DS, Kim SK and Bae H: Therapeutic effects of bee venom on immunological and neurological diseases. Toxins (Basel) 7: 2413-2421, 2015

16. Khamis AA, Ali EM, El-Moneim MA, Abd-Alhaseeb MM, El-Magd MA and Salim EI: Hesperidin, piperine and bee venom synergistically potentiate the anticancer effect of tamoxifen against breast cancer cells. Biomed Pharmacother 105: $1335-1343,2018$

17. Lee JD, Kim SY, Kim TW, Lee SH, Yang HI, Lee DI and Lee YH: Anti-inflammatory effect of bee venom on type II collagen-induced arthritis. Am J Chin Med 32: 361-367, 2004.

18. Zatroch KK, Knight CG, Reimer JN and Pang DS: Refinement of intraperitoneal injection of sodium pentobarbital for euthanasia in laboratory rats (Rattus norvegicus). BMC Vet Res 13: 60, 2017.

19. Liu YL, Lin HM, Zou R, Wu JC, Han R, Raymond LN, Reid PF and Qin ZH: Suppression of complete Freund's adjuvant-induced adjuvant arthritis by cobratoxin. Acta Pharmacol Sin 30: 219-227, 2009.

20. Lewis A and Levy A: Anti-inflammatory activities of Cassia alata leaf extract in complete Freund's adjuvant arthritis in rats. West Indian Med J 60: 615-621, 2011

21. Banji D, Pinnapureddy J, Banji OJ, Kumar AR and Reddy KN: Evaluation of the concomitant use of methotrexate and curcumin on Freund's complete adjuvant-induced arthritis and hematological indices in rats. Indian J Pharmacol 43: 546-550, 2011

22. Chung JI, Barua S, Choi BH, Min BH, Han HC and Baik EJ: Anti-inflammatory effect of low intensity ultrasound (LIUS) on complete Freund's adjuvant-induced arthritis synovium. Osteoarthritis Cartilage 20: 314-322, 2012.

23. Larsson P, Kleinau S, Holmdahl R and Klareskog L: Homologous type II collagen-induced arthritis in rats. Characterization of the disease and demonstration of clinically distinct forms of arthritis in two strains of rats after immunization with the same collagen preparation. Arthritis Rheum 33: 693-701, 1990.

24. Mossiat C, Laroche D, Prati C, Pozzo T, Demougeot C and Marie C: Association between arthritis score at the onset of the disease and long-term locomotor outcome in adjuvant-induced arthritis in rats. Arthritis Res Ther 17: 184, 2015.

25. Jou JM, Lewis SM, Briggs C, Lee SH, De La Salle B and McFadden S; International Council for Standardization in Haematology: ICSH review of the measurement of the erythocyte sedimentation rate. Int J Lab Hematol 33: 125-132, 2011.

26. Kyei S, Koffuor GA and Boampong JN: Antiarthritic effect of aqueous and ethanolic leaf extracts of Pistia stratiotes in adjuvant-induced arthritis in Sprague-Dawley rats. J Exp Pharmacol 4: 41-51, 2012

27. Petrovic-Rackov L and Pejnovic N: Clinical significance of IL-18, IL-15, IL-12 and TNF-alpha measurement in rheumatoid arthritis. Clin Rheumatol 25: 448-452, 2006.

28. Klopfleisch R: Multiparametric and semiquantitative scoring systems for the evaluation of mouse model histopathology-a systematic review. BMC Vet Res 9: 123, 2013.

29. Darwish SF, El-Bakly WM, Arafa HM and El-Demerdash E: Targeting TNF- $\alpha$ and NF- $\kappa$ B activation by bee venom: Role in suppressing adjuvant induced arthritis and methotrexate hepatotoxicity in rats. PLoS One 8: e79284, 2013.

30. Blobaum AL and Marnett LJ: Structural and functional basis of cyclooxygenase inhibition. J Med Chem 50: 1425-1441, 2007

31. Maclouf J, Grassi J and Pradelles P: Development of enzyme-immunoassay techniques for measurement of eicosanoids. In: Prostaglandin and Lipid Metabolism in Radiation Injury. Springer, pp355-364, 1987.

32. Vyas S, Agrawal RP, Solanki P and Trivedi P: Analgesic and anti-inflammatory activities of Trigonella foenum-graecum (seed) extract. Acta Pol Pharm 65: 473-476, 2008.

33. Morris CJ: Carrageenan-induced paw edema in the rat and mouse. Methods Mol Biol 225: 115-121, 2003.

34. Domiati S, El-Mallah A, Ghoneim A, Bekhit A and El Razik HA: Evaluation of anti-inflammatory, analgesic activities, and side effects of some pyrazole derivatives. Inflammopharmacology 24: $163-172,2016$
35. Taber RI, Greenhouse DD, Rendell JK and Irwin S: Agonist and antagonist interactions of opioids on acetic acid-induced abdominal stretching in mice. J Pharmacol Exp Ther 169: 29-38, 1969.

36. Young HY, Luo YL, Cheng HY, Hsieh WC, Liao JC and Peng WH: Analgesic and anti-inflammatory activities of (6)-gingerol. J Ethnopharmacol 96: 207-210, 2005.

37. Ghosh MN: Fundamentals of experimental pharmacology. Indian J Pharmacol 39: 216, 2007.

38. Yang RZ, Park S, Reagan WJ, Goldstein R, Zhong S, Lawton M, Rajamohan F, Qian K, Liu L and Gong DW: Alanine aminotransferase isoenzymes: Molecular cloning and quantitative analysis of tissue expression in rats and serum elevation in liver toxicity. Hepatology 49: 598-607, 2009.

39. Husdan H and Rapoport A: Estimation of creatinine by the Jaffe reaction. A comparison of three methods. Clin Chem 14: 222-238, 1968

40. Safiri S, Kolahi AA, Hoy D, Smith E, Bettampadi D, Mansournia MA, Almasi-Hashiani A, Ashrafi-Asgarabad A, Moradi-Lakeh M, Qorbani M, et al: Global, regional and national burden of rheumatoid arthritis 1990-2017: A systematic analysis of the global burden of disease study 2017. Ann Rheum Dis 78: $1463-1471,2019$

41. Luo H, Zuo XX, Li T and Zhang J: Effect of bee venom on adjuvant induced arthritis in rats. Zhong Nan Da Xue Xue Bao Yi Xue Ban 31: 948-951, 2006 (In Chinese).

42. Kwon YB, Kang MS, Kim HW, Ham TW, Yim YK, Jeong SH, Park DS, Choi DY, Han HJ, Beitz AJ and Lee JH: Antinociceptive effects of bee venom acupuncture (apipuncture) in rodent animal models: A comparative study of acupoint versus non-acupoint stimulation. Acupunct Electrother Res 26: 59-68, 2001.

43. Kocyigit A, Guler EM and Kaleli S: Anti-inflammatory and antioxidative properties of honey bee venom on freund's complete adjuvant-induced arthritis model in rats. Toxicon 161: 4-11, 2019.

44. Gohil P, Patel V, Deshpande S, Chorawala M and Shah G: Anti-arthritic activity of cell wall content of Lactobacillus plantarum in freund's adjuvant-induced arthritic rats: Involvement of cellular inflammatory mediators and other biomarkers. Inflammopharmacology 26: 171-181, 2018.

45. Silva JC, Rocha MF, Lima AA, Brito GA, de Menezes DB and Rao VS: Effects of pentoxifylline and nabumetone on the serum levels of IL-1beta and TNFalpha in rats with adjuvant arthritis. Inflamm Res 49: 14-19, 2000.

46. Ahmed O, Fahim H, Mahmoud A and Eman Ahmed EA: Bee venom and hesperidin effectively mitigate complete freund's adjuvant-induced arthritis via immunomodulation and enhancement of antioxidant defense system. Arch Rheumatol 33: 198-212, 2017.

47. Kim HW, Kwon YB, Ham TW, Roh DH, Yoon SY, Kang SY, Yang IS, Han HJ, Lee HJ, Beitz AJ and Lee JH: General pharmacological profiles of bee venom and its water soluble fractions in rodent models. J Vet Sci 5: 309-318, 2004.

48. Vick JA and Shipman WH: Effects of whole bee venom and its fractions (apamin and melittin) on plasma cortisol levels in the dog. Toxicon 10: 377-380, 1972.

49. Chang DM, Baptiste P and Schur PH: The effect of antirheumatic drugs on interleukin 1 (IL-1) activity and IL-1 and IL-1 inhibitor production by human monocytes. J Rheumatol 17: 1148-1157, 1990.

50. Kane D, Gogarty M, O'Leary J, Silva I, Bermingham N, Bresnihan B and Fitzgerald O: Reduction of synovial sublining layer inflammation and proinflammatory cytokine expression in psoriatic arthritis treated with methotrexate. Arthritis Rheum 50: 3286-3295, 2004

51. Segal R, Mozes E, Yaron M and Tartakovsky B: The effects of methotrexate on the production and activity of interleukin-1. Arthritis Rheum 32: 370-377, 1989.

52. Lucas S: The pharmacology of indomethacin. Headache 56: 436-446, 2016

53. Todd PA and Sorkin EM: Diclofenac sodium. A reappraisal of its pharmacodynamic and pharmacokinetic properties, and therapeutic efficacy. Drugs 35: 244-285, 1988.

54. Nam KW, Je KH and Lee JH: Inhibition of COX-2 activity and proinflammatory cytokines (TNF-alpha and IL-1beta) production by water-soluble sub-fractionated parts from bee (Apis mellifera) venom. Arch Pharm Res 26: 383-388, 2003

55. Park HJ, Lee SH, Son DJ, Oh KW, Kim KH, Song HS, Kim GJ, Oh GT, Yoon DY and Hong JT: Antiarthritic effect of bee venom: Inhibition of inflammation mediator generation by suppression of NF-kappaB through interaction with the p50 subunit. Arthritis Rheum 50: 3504-3515, 2004 
56. Amin AR, Dave M, Attur M and Abramson SB: COX-2, NO, and cartilage damage and repair. Curr Rheumatol Rep 2: 447-453, 2000.

57. Ku EC, Lee W, Kothari HV and Scholer DW: Effect of diclofenac sodium on the arachidonic acid cascade. Am J Med 80: 18-23, 1986

58. Junger $\mathrm{H}$ and Sorkin LS: Nociceptive and inflammatory effects of subcutaneous TNFalpha. Pain 85: 145-151, 2000.

59. Leung L and Cahill CM: TNF-alpha and neuropathic pain-a review. J Neuroinflammation 7: 27, 2010.

60. Dirig DM, Isakson PC and Yaksh TL: Effect of COX-1 and COX-2 inhibition on induction and maintenance of carrageenan-evoked thermal hyperalgesia in rats. J Pharmacol Exp Ther 285: 1031-1038, 1998 .
61. Han SM, Lee GG and Park KK: Acute dermal toxicity study of bee venom (Apis mellifera L.) in Rats. Toxicol Res 28: 99-102, 2012.

62. Han SM, Lee KG, Yeo JH and Pak SC: Dermal and ocular irritation studies of honeybee (Apis mellifera L.) venom. Am J Chin Med 40: 795-800, 2012.

63. Grisotto LS, Mendes GE, Castro I, Baptista MA, Alves VA, Yu L and Burdmann EA: Mechanisms of bee venom-induced acute renal failure. Toxicon 48: 44-54, 2006.

This work is licensed under a Creative Commons Attribution-NonCommercial-NoDerivatives 4.0 International (CC BY-NC-ND 4.0) License. 